\title{
PERAN GURU PADA ERA PENDIDIKAN 4.0
}

\author{
METHA LUBIS \\ Dosen Pendidikan Ekonomi, Universitas Pamulang \\ dosen02252@unpam.ac.id
}

\begin{abstract}
ABSTRAK
Era revolusi industri 4.0 mengakibatkan perubahan diberbagai bidang termasuk Pendidikan. Penelitian ini mengkaji bagaimana peran guru dalam mengajar di era Pendidikan 4.0. Metode dalam penelitian ini adalah studi literatur. Penelitian studi literatur ini menggunakan berbagai sumber tertulis seperti jurnal dan dokumen- dokumen yang relevan terhadap penelitian ini. Studi ini memfokuskan pada peran guru sebagai seorang pendidik dalam pendidikan dan pembelajaran. Peran penting guru adalah dalam memajukan pendidikan, ini karena guru berinteraksi langsung dengan siswa dalam pembelajaran. Guru sebagai pendidik didalam pembelajaran pada era Pendidikan 4.0 ini harus memiliki soft skill yang kuat, antara lain: critical thingking, creative, communicative dan collaborative (Cann, 2016). Hasil studi menunjukkan bahwa peran guru tidak dapat tergantikan sepenuhnya oleh teknologi. Peran guru yang tidak dapat digantikan tersebut antara lain: teladan dalam tindakan, sikap ataupun karakter dan inspiratif serta pasion. Interaksi guru dan siswa dalam pembelajaran dapat membangun dan mengembangkan karakter siswa.
\end{abstract}

Kata Kunci: peran, guru, pendidikan 4.0 


\section{PENDAHULUAN}

Revolusi industri 4.0 terjadi sekitar tahun 2010. Perkembangan industri 4.0 berdampak terhadap berbagai bidang termasuk dalam bidang pendidikan. Proses dalam kegiatan belajar mengajar saat ini memanfaatkan teknologi digital (Davis, 2015). Kompetensi guru pun harus ditingkatkan untuk mengikuti arus perkembangan informasi dan teknologi (Kagermann, 2014).

Guru sebagai pemimpin dalam pembelajaran dituntuk untuk mampu beradaptasi dan siap berubah, agar dapat menghadapi tantangan di era industri 4.0 (Burritt and Christ, 2016). Guru diperlukan untuk membentuk karakter siswa, teladan yang menumbuhkan semangat, kreativitas dan empati sosial.

Di era industri 4.0 siswa harus dibekali dengan keterampilan antara lain: berpikir kritis, memecahkan masalah, kreatif, inovatif, dan berkomunikasi serta berkolaborasi. Siswa di era Pendidikan 4.0 dituntut memiliki kemampuan yang terampil menggunakan teknologi baik dalam mencari, mengelola, dan maupun menyampaikan informasi ( Hussin, 2018).

Keterampilan yang harus dimiliki siswa menurut Wold Economic Forum (2016) meliputi: (1) Complex Problem Solving, (2) coordinating with others, (3) people management, (4) critical thinking,
(5) negotiation, (6) quality control, (7) service orientation, (8) judgement and decision making, (9) active learning, dan (10) creativity, hingga dapat memenuhi tuntutan kebutuhan masa mendatang (Jack Ma, 2018).

Keterampilan tersebut harus dikuasai siswa agar dapat memenuhi tuntutan kebutuhan industri dimasa mendatang. Pemerintah Indonesia telah menyiapkan kurikulum yang menekankan pada STEAM (Science, Technology, Engineering, the Arts, and Mathematics) untuk mencapai kesuksesan pelaksanaan peta jalan Making Indonesia (Hartanto, 2018).

Pemerintah sedang berusaha meningkatkan mutu sumber daya manusia. Sumber daya manusia yang berkualitas unggul akan dihasilkan dari guru yang mampu menguasai teknologi yang super cepat. Oleh sebab itu, untuk menjawab tantangan di era Pendidikan 4.0 guru tidak hanya merubah cara mengajar tetapi harus mampu meningkatkan dan menyesuaikan kompetensi, kualitas dan profesionalitas.

Peningkatan SDM ini guna memenuhi permintaan industri mendatang. Dalam meningkatkan SDM ini, maka guru berperan dalam membangun kemampuan siswa. Peran guru di era Pendidikan 4.0 tidak akan tergantikan oleh teknologi sehebat apapun. Guru tidak hanya untuk mengisi ilmu pengetahuan siswa, namun guru memiliki peran dalam mendidik karakter, etika, moral siswa. Peran inilah yang tidak 
bisa digantikan oleh teknologi apapun.

\section{METODE PENELITIAN}

Penelitian ini menggunakan penelitian Studi Literatur, dimana dilakukan pengumpulan data melalui pencarian informasi menggunakan buku, artikel maupun literaturliteratur yang lainnya (Brooks and Simon, 2013). Literatur yang digunakan adalah literatur yang berhubungan dengan pendidikan 4.0, perkembangan industri 4.0, sehingga terbentuklah landasan teori. Landasan teori ini digunakan untuk menganalisis bagaimana peran guru di era Pendidikan 4.0.

\section{HASIL DAN PEMBAHASAN \\ Pendidikan 4.0}

Perkembangan bidang teknologi melahirkan tantangan baru di era indutri 4.0, salah satunya adalah pendidikan. Dimana pendidikan akan mencetak sumber daya manusia. Dengan berkembangnya teknologi ini, maka SDM dituntut memiliki berbagai keterampilan untuk memenuhi kebutuhan industri di masa mendatang.

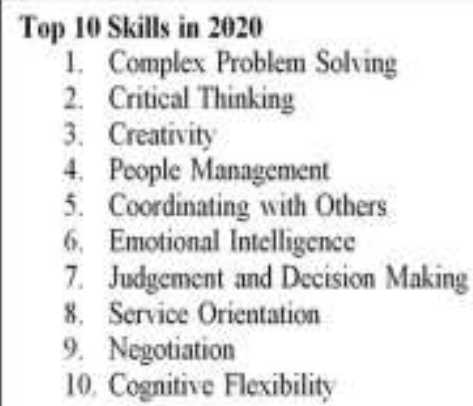

Gambar 1. Keterampilan Siswa di Era Pendidikan 4.0

Pendidikan 4.0 adalah suatu istilah yang digunakan oleh para ahli dalam mengintegrasikan teknologi cyber dalam pembelajaran (Davis, 2015). Pendidikan di era industri 4.0 ini lebih memanfaatkan teknologi digital. Oleh karena itu, pendidikan di industri 4.0 perlu mengembangkan kemampuan, diantaranya: berpikir, bertindak dalam berinovasi serta kreatif (Greenstein, 2012).

Pendidikan pada abad ini mengalami tantangan yang sangat besar (Jack Ma, 2018). Jika cara mengajar tidak dirubah maka kita akan mengalami kesulitan besar. Pembelajaran harus memuat keterampilan dan sikap, agar siswa mampu berkompetisi dengan mesin. Siswa pada Pendidikan 4.0 dalam produksi dan aplikasi pengetahuan serta inovasi sebagai konektor, kreator, dan konstruktivis (BrownMartin, 2017). Inilah yang menyebabkan kita harus menyiapkan guru yang berkualitas, dan 
berkompeten serta memiliki kualifikasi.

\section{Guru di Era Pendidikan 4.0}

\section{Era Pendidikan 4.0}

menekankan pada ekonomi digital, intelegensi artifisial, robot dan data (Ghani and Kamaruzzaman, 2019). Sehingga dunia pendidikan dan pembelajaran mengalami perubahan. Tuntutan di era pendidikan 4.0 ini, guru mendapatkan tantangan untuk mengubah cara pandang dan metode dalam pembelajaran (King, et al., 2010).

Guru pada era pendidikan 4.0 ini jika tidak memiliki kualitas, kompetensi dan kualifikasi yang mumpuni, maka akan tergantikan salah satu fungsinya yaitu dalam mentransfer ilmu pengetahuan (Almeida: 2019). Guru harus cepat menanggapi perubahan ini. Dengan kata lain, guru memiliki tugas lebih dari sekedar mengajar, namun juga mengelola siswa.

Peran guru dalam pendidikan dan pembelajaran akan menjadi teladan bagi siswa. Guru perlu melakanakan pembelajaran dengan menyenangkan, menarik, kreatif, bersahabat, dan fleksibel (Leen, et al., 2014). Selain itu, guru juga menjadi fasilitator, inspirator, motivator, imajinasi, kreativitas dan tim kerja serta pengembang nilai nilai karakter. Dan juga guru merupakan empati sosial untuk siswa. Hal tersebut diatas merupakan peran guru yang tidak akan dapat digantikan oleh teknologi.
Guru harus melatih keterampilan untuk menghadapi era pendidikan 4.0. keterampilan yang dikuasai guru akan dapat melatih keterampilan siswa.

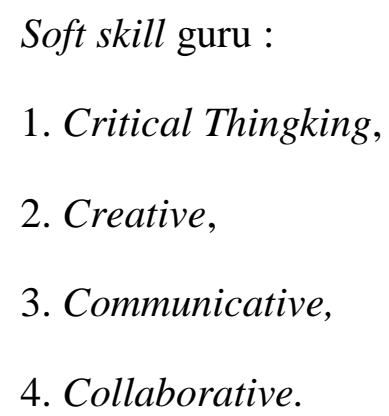

Guru juga harus mampu memenuhi kebutuhan psikologis siswa. Kebutuhan psikologis siswa tersebut diantaranya: (1) needs for competence, (2) needs for autonomy, (3) needs for relatedness, dan (4) sustainble learning (Chou, et al., 2018)

Hal demikianlah yang membuat peran guru tak tergantikan oleh teknologi sehebat apapun. Ini karena teknologi tak dapat menjadi fasilitator, inspirator, motivator, imajinasi, kreativitas, empati sosial, dan tim kerja serta pengembang nilai- nilai karakter. Namun, guru tetaplah diharapkan untuk selalu dapat mengembangkan kompetensi agar menghasilkan pendidikan berkualitas.

\section{KESIMPULAN}

Studi literatur mengenai peran guru dalam pendidikan 4.0 menghasilkan pemahaman bahwa: (1) perkembangan industri 4.0 
merupakan tantangan besar bagi dunia pendidikan. (2) fungsi guru bukan hanya transfer ilmu. (3) guru memiliki peran penting dalam pendidikan dan pembelajaran. (4) guru di era Pendidikan 4.0 harus meningkatkan keterampilan agar menghasilkan lulusan yang siap menghadapi industri 4.0. (5) guru harus mampu memenuhi kebutuhan psikologis siswa. (6) peran guru sebagai fasilitator, inspirator, motivator, imajinasi, kreativitas, empati sosial, dan tim kerja serta pengembang nilai- nilai karakter tidak dapat digantikan oleh teknologi.

\section{DAFTAR PUSTAKA}

Almeida, Fernando. 2019. The Role of Serious Games, Gamification And Industry 4.0 Tools In The Education 4.0 Paradigm. Contemporary Educational Technology, 10(2), 120-136.

Brooks, Gavin. and Simon Bibby. 2013. The Journal of Literature In Language Teaching, Vol. 2, ISSN: 2187$722 \mathrm{X}$

Brown-Martin, G. 2017. Education and the fourth industrial revolution.

https://www.groupemediatfo.or g/wpcontent/uploads/2017/12/ FINAL.

Burritt, R. and K. Christ, 2016. Industry 4.0 and environmental accounting: A new revolution?
Asian Journal of Sustainability and Social Responsibility, 1(1): 23-38.

Cann, O., 2016. Five million jobs by 2020: The real challenge of the fourth industrial revolution. World Economic Forum. International Organisation for Public Private Cooperation, Geneva, Switzerland. Available from

https://www.weforum.org/pres s/2016/01/five-million-jobs-by2020-the-real-challenge-of-thefourth-industrial-revolution/.

Chou, Chun-Mei, Chien-Hua Shen, His-Chi Hsiao, and TsuChguan Shen. 2018. Industry 4.0 Manpower and its Teaching Connotation in Technical and Vocational Education: Adjust 107 Curriculum Reform. International Journal of Psychology and Educational Studies, 2018, 5 (1), 9-14.

Davis, R., 2015. Industry 4.0: Digitalisation for productivity and growth, briefing for the European parliament (PE568.337). European Parliamentary Research Service.

Ghani, Erlane K. and kamaruzzaman. 2019. Industry 4.0: Employers' Expectations of Accounting Graduates and its Implications on Teaching and Learning Practices. International Journal of Education and 
Practice, Vol. 7, no. 1, pp. 1929, ISSN(e): 2310-3868, ISSN(p): 2311-6897.

Greenstein, L. 2012. Assessing 21 st Century skills: A guide to evaluating mastery and authentic learning. Thousand Oaks, CA: Corwin.

Hartanto, A. 2018. Making Indonesia 4.0. Jakarta. Retrieved from http://www.kemenperin.go.id/d ownload/18384

Hussin, A. A. 2018. Education 4.9 Made Simple: Ideas For Teaching. International Journal of Education \& Literacy Studies, 6(3), 92-98.

Jack Ma. 2018. World Economic Forum. Davos, Swiss. Diakses tanggal 24 November 2019. https://www.liputan6.com/bisni s/read/3238241/jack-ma-ubahpendidikan-agar-bersaingdengan robot

Kagermann, H., 2014. Chancen von industrie 4.0 nutzen, In $T$. Bauernhansl, M. ten Hompel \& B. Vogel-Heuser, (Ed.). Industrie 4.0 in Produktion, Automatisierung und Logistik. Anwendungen Technologien Migration. Wiesbaden: Springer. pp: 603-614.

Leen, C.C., Hong, K.F.F.H., and Ying, T.W. 2014. Creative and Critical Think-ing in Singapore Schools. Singapore: Nanyang Technological University
World Economic Forum. 2016a. Chapter 1: The future of jobs and skills. Accessed from http://reports.weforum.org/futu re-of-jobs-2016/chapter-1-thefuture-of-jobs-and-skills

World Economic Forum Report. 2016b. New Vision for Education: Fostering social and emotional learning through technology. 